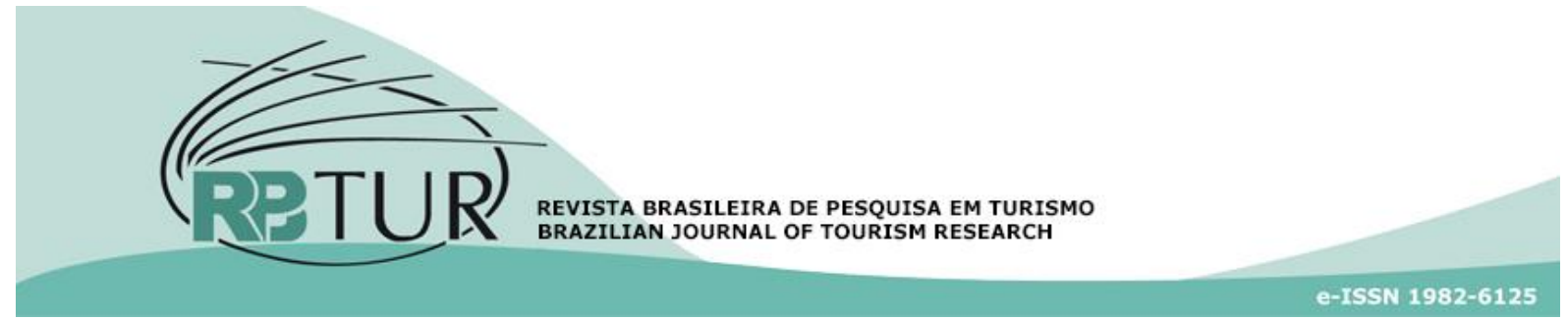

Artigo

DOI: http://dx.doi.org/10.7784/rbtur.v11i1.1105

\title{
Análise de citações de periódicos científicos de turismo no Brasil: subsídios para a estimação de indicadores de impacto
}

\section{Citation analysis of the Brazilian tourism journals: subsidies for the estimation of impact factors}

\section{Análisis de citas de periódicos científicos de turismo en Brasil: subsidios para la estimación de indicadores de impacto}

\author{
Glauber Eduardo de Oliveira Santos ${ }^{1}$ \\ Alexandre Panosso Netto ${ }^{2}$ \\ Xuanyi Wang ${ }^{3}$
}

Resumo: O artigo apresenta a análise de todas as referências feitas pelos artigos publicados nas quatro principais revistas de turismo do Brasil. Foram identificadas 28.767 referências nos 1.254 artigos publicados desde o primeiro volume de cada revista até o fim de 2014. As referências foram analisadas quanto ao tipo de material (periódico, livro, tese, trabalho em evento e outros), local de publicação (Brasil ou exterior) e autoria. Nos casos de referências feitas a artigos científicos, foram identificados os nomes dessas publicações específicas. Os resultados apontam os autores, livros, artigos e periódicos mais citados. Foram também estimados os fatores de impacto dos periódicos e os índices h de Hirsch (2005) dos autores. Além disso, foram utilizadas técnicas de análise de redes sociais para representar as relações existentes entre os autores e entre os periódicos, além de estimar índices complexos de centralidade desses agentes. Os resultados apontam tendências de mudança do cenário atual decorrentes do fortalecimento de novos autores e periódicos.

Palavras-chave: Turismo. Periódicos Científicos. Análise Bibliométrica. Fator de Impacto. Brasil.

Abstract: This paper presents the analysis of all references made by articles published at the four major Brazilian tourism journals. A total of 28,767 references in the 1,254 articles published since the first volume of each journal until the end of 2014. References were analyzed with respect to their type (journal, book, thesis, conference paper

1 Escola de Artes, Ciências e Humanidades da Universidade de São Paulo (EACH-USP), São Paulo, SP, Brasil. Desenvolvimento metodológico, processamento e análise de dados.

2 Escola de Artes, Ciências e Humanidades da Universidade de São Paulo (EACH-USP), São Paulo, SP, Brasil. Projeto de pesquisa e provisão de recursos.

3 Escola de Artes, Ciências e Humanidades da Universidade de São Paulo (EACH-USP), São Paulo, SP, Brasil. Coleta de dados.

Artigo recebido em: 13/02/2016. Artigo aprovado em: 20/10/2016. 
and others), place of publishing (Brazil or other countries) and authorship. For the references of scientific articles, the names of these specific vehicles were identified. The results indicate the most cited authors, books, articles and journals. Impact factors of journals and the $h$-index of Hirsch (2005) of authors were also estimated. Moreover, techniques of social network analysis were applied to the representation of the relationships between authors and journals, besides estimating complex centrality indexes for these agents. The results also indicate some tendencies of change in the actual scenario arising from the strengthening of new authors and journals.

Keywords: Tourism. Scientific Journals. Bibliometric Analysis. Impact Factor. Brazil.

Resumén: En este trabajo se presenta un análisis de todas las referencias de los artículos publicados en los cuatro principales periódicos de turismo de Brasil. Se identificaron 28.767 referencias de 1.254 artículos publicados desde el primer volumen de cada periódico hasta el final de 2014. Las referencias fueron analizadas con respecto al tipo de material (periódico, libro, tesis, trabajando en congresos y otros), lugar de publicación (Brasil o exterior) y la autoría. En el caso de referencias a artículos científicos, se identificaron los nombres de las publicaciones específicas. Los resultados apuntan a los autores, libros, artículos y periódicos más citados. También se estimaron los factores de impacto de las revistas y el índice $h$ de Hirsch (2005) de los autores. Se utilizaron técnicas de análisis de redes sociales para representar la relación entre los autores y entre los periódicos, además de estimar índices complejos de la centralidad de estos agentes. Los resultados también indican cambios en las tendencias de la situación actual resultantes de la consolidación de nuevos autores y las revistas.

Palabras clave: Turismo. Periódicos Científicos. Análisis Bibliométrico. Factor de Impacto. Brasil.

\section{INTRODUÇÃO}

A análise da produção científica de um país, seja ela relativa a todas as áreas ou especificamente de uma área de pesquisa, é fundamental para indicar os rumos que a ciência está seguindo, seus desdobramentos, evitar possíveis equívocos e corrigir rotas. Segundo estudo da FAPESP (2005), o uso de indicadores têm longa tradição, pois estes são ferramentas para impulsionar a ciência, a tecnologia, a inovação e a competitividade e podem contribuir "para a análise dos resultados da infraestrutura disponível e das políticas de investimento em pesquisa científica e tecnológica" (p. 4). Portanto, trata-se de um exercício teórico com resultados práticos que tem ganhado cada vez mais visibilidade na comunidade científica brasileira. A bibliometria é o campo da biblioteconomia e da ciência da in- formação responsável por esta análise a partir de dados que, após tratamentos, geram in dicadores variados do que se está pesquisando.

De acordo com Santos e Rejowski (2013), já existiram no Brasil ao menos 20 periódicos científicos de turismo. Os mesmos autores apontam que são várias as dificuldades que os periódicos brasileiros encontram, entre elas: não constam no Journal Citation Reports da Thomson Reuters, não possuem fator de impacto, não são indexados na Scientific Electronic Library Online (SCIELO) e não integram outros sistemas de arquivamento, tais como Science Direct, Sage Publications e JSTOR.

$O$ presente artigo insere-se no contexto da análise bibliométrica e analisa as referências feitas pelos artigos publicados nas quatro revistas científicas brasileiras de tu- 
rismo melhor classificadas pelo sistema Qualis da CAPES em 2014, sendo elas: Caderno Virtual de Turismo (CVT), Revista Brasileira de Pesquisa em Turismo (RBTur), Revista Turismo em Análise (RTA) e Revista Turismo Visão e Ação (RTVA). O objetivo principal é desenvolver a análise bibliométrica e oferecer subsídios para a criação de indicadores de impacto das revistas científicas de turismo brasileiras. Para tanto, a seção a seguir traz uma breve revisão da literatura sobre bibliometria e a produção científica de turismo no Brasil. A seção 3 descreve o conjunto de artigos analisados. A seção 4 apresenta os resultados obtidos, incluindo informações sobre o tipo de referência, os principais artigos e livros brasileiros de turismo referenciados e a autoria destes, os periódicos citados e os temas abordados nos trabalhos referenciados. Em particular, são apresentados diferentes indicadores de impacto dos periódicos e dos autores, incluindo fatores de impacto, índices h e medidas de centralidade das redes sociais formadas pelas referências.

\section{REVISÃO DA LITERATURA}

As análises mais robustas da produção científica brasileira são feitas por organizações públicas, entre elas CNPq (2016), CAPES (vários relatórios disponíveis em www.capes.gov.br) e FAPESP (2005). Porém há autores que se especializaram neste tipo de investigação, entre eles Viotti e Macedo (2003), Mugnaini, Jannuzzi e Quoniam (2004) e Meis, Arruda e Guimarães (2007), apenas para citar alguns.

Análises bibliométricas geralmente focam-se no tratamento das referências feitas por trabalhos científicos. Tais referências podem incluir livros, revistas, artigos de revistas, artigos publicados em eventos e outros. As análises são feitas por meio de diferentes métodos estatísticos, podendo ou não ser específicas de uma área, a depender dos objetivos a serem atingidos. Os objetivos desse tipo de estudo podem incluir a identificação de tendências de desenvolvimento ou de decadência de uma área; a mensuração a contribuição dada por universidades, grupos de estudos, pesquisadores e revistas científicas; e a identificação de relações entre pesquisadores, temas de estudos, grupos, universidades, etc. Tais análises tem sido utilizadas no Brasil por diferentes áreas do conhecimento, como, por exemplo, a administração (Bertero, Caldas, \& Wood Jr., 1999; Wood Jr \& Chueke, 2008), medicina (Mendes, Martelli, Souza, Quirino Filho, \& Martelli Júnior, 2010; Romano-Silva et al., 2013; Vitor-Costa, Silva, \& Soriano, 2012) e Educação Física (Sacardo \& Hayashi, 2011; Vitor-Costa et al., 2012).

A produção científica brasileira em turismo, se comparada a outras áreas já estabelecidas, é recente e está em busca da excelência e elevação de sua qualidade. Sobre os livros, quando (Barretto, 1996, p. 99) fez o primeiro levantamento do que havia publicado no Brasil, foram identificados 66 livros. Segundo Panosso Netto (2005), a primeira série de turismo do Brasil surgiu em 1986, com "Turismo: atividade marcante do século XX", de Geraldo Castelli (Editora Educs). Esse autor inventariou 329 títulos que haviam sido publicados por 17 editoras entre 1990 e 2004. Posteriormente, Panosso Netto e 
Calciolari (2010), numa atualização, chegaram ao número de 51 editoras que publicaram 560 títulos. Na atualidade Santos (2016) inventaria por volta de 1700 livros de turismo já publicados no Brasil.

Em relação às revistas científicas de turismo no mundo, de acordo com Panosso Netto e Jäger (2015), a primeira foi criada na Alemanha antes mesmo da Segunda Guerra Mundial, pelo pesquisador Robert Glücksmann em 1930 e intitulava-se Archiv für den Fremdenverkehr (Arquivo de/para o Turismo). Em 1946 nasceu a Revue du Tourisme, na Suíça, ativa até hoje. Outras revistas surgiram somente na década de 1960. Estudos sobre as mais importantes revistas internacionais de turismo foram publicados por Pechlaner, Zehrer, Matzler e Abfalter (2004), Ryan (2005), McKercher, Law e Lam (2006), Jamal, Smith e Watson (2008), Severt, Tesone, Bottorff e Carpenter (2009), Hall (2011), Cheng, Li, Petrick e O'Leary (2011), Park, Phillips, Canter e Abbott (2011). Moreno-Gil e Picazo-Peral (2012) abordaram apenas os artigos científicos publicados em diferentes periódicos por autores filiados a entidades espanholas.

Segundo Rejowski e Aldrigui (2007), no que se refere às revistas científicas em turismo no Brasil, a primeira a ser criada foi a Revista Turismo em Análise, da USP, em 1990 e a segunda foi o Boletim do Curso de Turismo (desativada), da UNIBERO, em 1992. Em 1998 surgiram a Turismo: Visão e Ação, da UNIVALI, e a Turismo: Tendências \& Debates, da Faculdade de Turismo da Bahia. O levantamento mais atual é o de Santos (2016), que indica a existência de 17 periódicos ativos na atualidade e outros 14 desativados. Solha e Jacon (2010) foram os primeiros a proporem uma análise qualitativa dos periódicos e não somente quantitativa, o que foi seguido por Miranda (2012).

Ainda com foco no Brasil, PicazoPeral, Moreno-Gil e León-González (2012) analisaram a contribuição dos pesquisadores de turismo filiados a entidades brasileira publicada em revistas especializadas na área tanto no país quanto fora no período de 2006 a 2011. Foram identificadas as principais instituições de ensino e pesquisadores brasileiros, ranqueando-os comparativamente. Apesar de receber críticas ao ser visto como um artigo que fortalece a lógica produtivista na academia, o estudo oferece um panorama, a partir de critérios objetivos pré-determinados, sobre quem são os brasileiros que mais publicam em um grupo de revistas científicas. A pesquisa de Santos e Rejowski (2013) ampliou a pesquisa de Picazo-Peral et al. (2012) ao analisar 2.126 artigos publicados em 20 periódicos científicos brasileiros de turismo entre 1990 e 2012. Foram identificados os autores mais profícuos e as palavras chaves mais recorrentes, além de estatísticas sobre tamanho dos artigos, títulos e resumos, configurando-se este num dos estudos mais completos sobre o tema.

É importante ressaltar que nenhum autor brasileiro de turismo ou instituição de ensino brasileira de turismo figura nos vários rankings internacionais já feitos por Ryan (2005), Pechlaner et al. (2004), Severt et al. (2009) ou Park et al. (2011). Os motivos para este fato até o momento não foram investigados e pairam no campo das hipóteses, en- 
tre elas a dificuldade do idioma inglês, o elevado custo para tradução ou correção do artigo em outro idioma, a escolha de temas que apresentam apenas interesse local, a deficiência metodológica e teórica dos pesquisadores ou até mesmo a falta de interesse em publicar em tais veículos de divulgação científica.

\section{ARTIGOS ANALISADOS}

Nesta pesquisa foram analisadas as referências utilizadas pelos artigos científicos publicados em quatro dos principais periódicos científicos de turismo do Brasil desde seus lançamentos até o fim de 2014 . A seleção desses periódicos partiu da classificação do sistema brasileiro Qualis, desenvolvido pela Coordenação de Aperfeiçoamento de Pessoal de Nível Superior (Capes). Foram selecionados os periódicos da área de turismo com classificação mínima B2 de acordo com a lista vigente em 2014. Uma vez que o foco de análise deste trabalho é a área de turismo como um todo, foi descartado o periódico $R e$ vista Brasileira de Ecoturismo (RBE) em razão do direcionamento específico dessa publicação, viés que poderia levar a distorções nos resultados em favor das pesquisas e pesquisadores ligados especificamente ao ecoturismo. Deve-se destacar que o sistema Qualis tem como objetivo a classificação dos periódicos científicos para fins de avaliação dos programas de pós-graduação. Portanto, a utilização desse instrumento para a seleção dos periódicos a serem analisados constitui um critério de aproximação à produção científica mais expressiva. Contudo, por não ter sido criado para este fim, tal instrumento está sujeito a eventuais distorções. Por outro lado, este critério foi utilizado por outros estudos semelhantes, como Santos e Rejowski (2013). Os periódicos selecionados para análise são descritos na Tabela 1.

Tabela 1 - Descrição dos periódicos analisados

\begin{tabular}{|c|c|c|c|c|c|}
\hline Periódico & Entidade responsável & $\begin{array}{l}\text { Ano de } \\
\text { início }\end{array}$ & $\begin{array}{l}\text { Qualis } \\
\text { (2014) }\end{array}$ & $\begin{array}{l}\text { Número } \\
\text { de artigos } \\
\text { analisados }\end{array}$ & $\begin{array}{l}\% \text { do total } \\
\text { de artigos } \\
\text { analisados }\end{array}$ \\
\hline $\begin{array}{l}\text { Caderno Virtual de Turismo } \\
\text { (CVT) }\end{array}$ & $\begin{array}{l}\text { Universidade Federal do } \\
\text { Rio de Janeiro (UFRJ) }\end{array}$ & 2001 & B1 & 308 & $24,6 \%$ \\
\hline $\begin{array}{l}\text { Revista Brasileira de Pes- } \\
\text { quisa em Turismo (RBTur) }\end{array}$ & $\begin{array}{l}\text { Associação Nacional de } \\
\text { Pesquisa e Pós-Graduação } \\
\text { em Turismo (ANPTUR) }\end{array}$ & 2007 & B2 & 156 & $12,4 \%$ \\
\hline $\begin{array}{l}\text { Revista Turismo em Análise } \\
\text { (RTA) }\end{array}$ & $\begin{array}{l}\text { Universidade de São Paulo } \\
\text { (USP) }\end{array}$ & 1990 & B2 & 473 & $37,7 \%$ \\
\hline $\begin{array}{l}\text { Revista Turismo Visão e Ação } \\
\text { (RTVA) }\end{array}$ & $\begin{array}{l}\text { Universidade do Vale do } \\
\text { Itajaí (UNIVALI) }\end{array}$ & 1998 & B2 & 317 & $25,3 \%$ \\
\hline Total & & & & 1254 & $100,0 \%$ \\
\hline
\end{tabular}

Os quatro periódicos selecionados para análise atualmente têm publicação quadrimestral. Em cada volume de cada periódico foram considerados apenas os trabalhos publicados na forma de artigos, sendo desconsiderados os trabalhos publicados em outras seções, tais como resenhas, comentários, relatos de eventos e outros. Durante a 
maior parte dos anos 1990 apenas a RTA foi publicada, sendo que a RTVA passou a ser publicada em 1998. Consequentemente, o número de artigos publicados durante aquela década representa uma parcela menor do total de artigos analisados (13,2\%). A maior parte dos artigos analisados $(55,8 \%)$ foram publicados a partir de 2008. Se considerado os 5 últimos anos do período em análise, o número de publicações representa $40,7 \%$ do total. A quantidade de artigos analisados por ano da publicação é apresentada na Figura 1.

Figura 1 - Ano de publicação dos artigos analisados

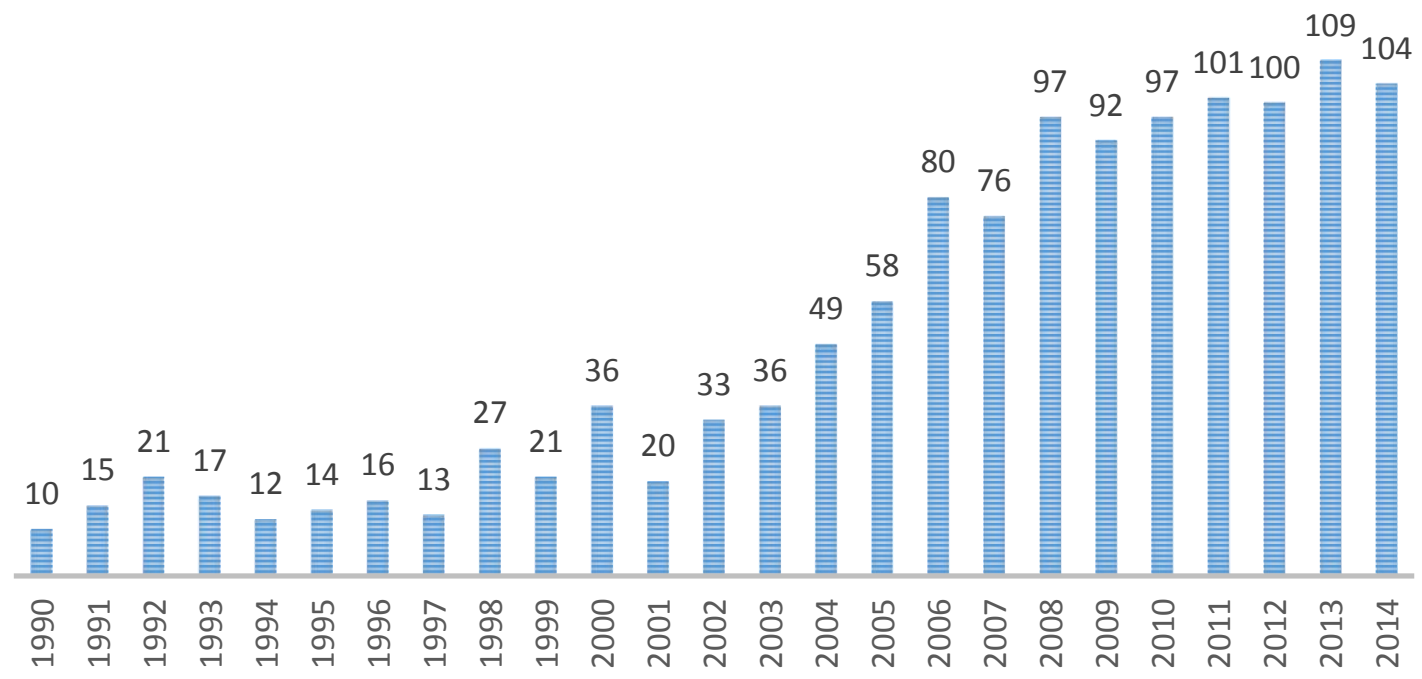

Pelo método da contagem simples de artigos, a pesquisadora Rivanda Meira Teixeira foi quem mais publicou no conjunto de periódicos analisado (22 artigos). Na sequência deste ranking aparecem Doris van de Meene Ruschmann (18 artigos), Mirian Rejowski (17 artigos) e José Manoel Gonçalves Gândara (17 artigos). Os 19 autores com 7 ou mais artigos incluídos no conjunto analisado são apresentados na Tabela 2 . Se continuada, esta lista indicaria a existência de 13 autores com 6 artigos publicados, 10 com 5 artigos, 25 com 4 artigos, 48 com 3 artigos, 210 com 2 artigos e 1460 com apenas 1 artigo. Portanto, nota-se que a distribuição de autores em função do número de artigos publicados segue uma curva aproximadamente exponencial, de forma que o número de autores diminui exponencialmente à medida que aumenta o número de artigos publicados.

As características dos artigos publicados não serão detalhadamente analisadas neste trabalho por uma questão de recorte do objeto de pesquisa. $O$ foco do presente artigo é a análise dos trabalhos citados, e não daqueles meramente publicados. Para informações sobre as características dos trabalhos publicados, recomenda-se o artigo de Santos e Rejowski (2013). 
Tabela 2 - Número de artigos analisados dos principais autores

\begin{tabular}{ll}
\hline Autor & Artigos \\
\hline Rivanda Meira Teixeira & 22 \\
Doris van de Meene Ruschmann & 18 \\
Mirian Rejowski & 17 \\
José Manoel Gonçalves Gândara & 17 \\
Carlos Alberto Cioce Sampaio & 11 \\
Glauber Eduardo de Oliveira Santos & 10 \\
Alfredo Ascanio & 10 \\
Paulo dos Santos Pires & 9 \\
Mario Carlos Beni & 9 \\
Josildete Pereira de Oliveira & 9 \\
Yolanda Flores e Silva & 8 \\
Francisco Antonio dos Anjos & 8 \\
Wilson Abrahão Rabahy & 7 \\
Valmir Emil Hoffmann & 7 \\
Maximiliano Emanuel Korstanje & 7 \\
Margarita Barretto & 7 \\
Heros Augusto Santos Lobo & 7 \\
Helena Araújo Costa & 7 \\
Edegar Luis Tomazzoni & 7 \\
\hline
\end{tabular}

\section{ANÁLISE DE RESULTADOS}

\subsection{Tipo de referência}

Foram registradas um total de 28.767 referências constantes ao fim de cada um dos 1254 artigos analisados. Estas foram classificadas em 5 categorias descritivas do tipo de material referenciado, a saber:

I. Periódico: trabalho publicado em periódico, independentemente da seção.

II. Livro: inclui livros autorais e livros organizados.

III. Tese: inclui teses doutorais, dissertações de mestrado e outros tipos de monografias acadêmicas.

IV. Evento: trabalhos apresentados em eventos ou publicados em anais de eventos.
V. Outros: outros tipos de materiais não incluídos nas categorias anteriores, tais como relatórios produzidos por organizações, páginas da Web, notícias de jornal e outros.

Uma pequena parcela dos materiais referenciados foi classificada na categoria outros (3,4\%). Como o foco desta pesquisa está voltado para os trabalhos autorais de natureza acadêmica, os materiais classificados como outros não foram analisados em detaIhe. Os trabalhos pertencentes às demais categorias foram também classificados quanto à nacionalidade e à área de conhecimento. No quesito nacionalidade, os materiais referenciados foram classificados em brasileiros ou estrangeiros. No quesito área de conhecimento, os materiais foram classificados como de turismo ou de outras áreas do conhecimento. No caso dos trabalhos publicados em periódicos, a classificação da área de conhecimento levou em conta o foco do periódico, e não do trabalho em si. Tanto para os periódicos como para outros materiais, o julgamento da existência de foco em turismo deuse pelos termos utilizados no título e descrição do material. Por exemplo, livros que não mencionavam o termo turismo nem no título e nem no resumo oficial divulgado pela editora foram classificados associados a outras áreas do conhecimento.

Dentre os 27.780 materiais autorais referenciados, a maior parte é composta por livros (57,2\%). Os trabalhos publicados em periódicos representam $32,1 \%$ do total de referências registradas. A proporção entre estes dois tipos de materiais tem apresentado tendência de mudança em favor dos periódi- 
cos. Apenas $1,2 \%$ dos livros referenciados foram publicados a partir de 2010, ao passo que $24,3 \%$ dos artigos referenciados a partir do mesmo ano.

A maioria do conjunto total de trabaIhos referenciados é brasileira (56,7\%). Os trabalhos específicos da área de turismo constituem apenas $38,1 \%$ do total de trabaIhos autorais registrados. Esse perfil das referências realizadas pelos artigos analisados revela que os autores têm preferência por referenciar trabalhos internacionais. Uma produção científica nacional mais consistente deve- ria levar à referenciação majoritária de periódicos nacionais de turismo. No entanto, as categorias mais citadas são justamente o contrário disto. Cada uma das três categorias associadas aos periódicos nacionais de turismo se revelou menos citada do que sua alternativa. Ao invés do esperado, as categorias de materiais mais citadas são livros, trabalhos estrangeiros e trabalhos de outras áreas do conhecimento. A distribuição das referências encontradas segundo estes três critérios de classificação é apresentada na Tabela 3.

Tabela 3 - Distribuição das referências analisadas segundo nacionalidade, área de conhecimento e tipo

\begin{tabular}{|c|c|c|c|c|c|c|c|}
\hline Tipo & $\begin{array}{l}\text { Turismo } \\
\text { Brasil }\end{array}$ & Exterior & Total & $\begin{array}{l}\text { Outra área } \\
\text { Brasil }\end{array}$ & Exterior & Total & Total \\
\hline Periódico & 876 & 2.766 & 3.642 & 1.686 & 3.580 & 5.266 & 8.908 \\
\hline Livro & 3.876 & 2.078 & 5.954 & 6.936 & 3.010 & 9.946 & 15.900 \\
\hline Tese & 409 & 66 & 475 & 937 & 95 & 1.032 & 1.507 \\
\hline Evento & 342 & 176 & 518 & 698 & 249 & 947 & 1.465 \\
\hline Total & 5.503 & 5.086 & 10.589 & 10.257 & 6.934 & 17.191 & 27.780 \\
\hline
\end{tabular}

Em média o tempo decorrido entre a publicação do trabalho e sua utilização como referência de um artigo científico é de 4,7 anos. A maioria das referências (59,5\%) são feitas a trabalhos até 4 anos mais velhos. Apenas $7,7 \%$ das citações se referem a trabaIhos com 10 ou mais anos de idade.

\subsection{Artigos e livros brasileiros de turismo}

As publicações em periódicos científicos e livros nacionais de turismo referenciadas no conjunto de artigos selecionados foram analisadas em maior nível de detalhe do que as demais publicações, incluindo os outros tipos de materiais, as publicações estran- geiras e os trabalhos de outras áreas do conhecimento. Ao todo foram feitas 876 referências a trabalhos publicados em periódicos científicos brasileiros de turismo. Essas referências dizem respeito a 547 trabalhos distintos e 7 citações de periódicos como um todo. Dos trabalhos autorais, apenas 12 foram citados ao menos 5 vezes. Metade destes foi publicada na RTA. O trabalho mais citado, publicado por Margarita Barretto na RTA em 2004, recebeu 10 citações. Os pesquisadores Mario Carlos Beni e Marta de Azevedo Irving são os únicos autores que contam com 2 trabalhos dentre os 12 mais citados. A lista dos 12 trabalhos que receberam ao menos 5 citações é apresentada na Tabela 4. 
Tabela 4 - Artigos brasileiros de turismo mais citados

\begin{tabular}{|c|c|c|c|c|}
\hline Título & Autor(es) & Periódico & Ano & Citações \\
\hline $\begin{array}{l}\text { Relações entre visitantes e visitados: um re- } \\
\text { trospecto dos estudos socioantropológicos }\end{array}$ & Margarita Barreto & RTA & 2004 & 10 \\
\hline $\begin{array}{l}\text { Plano Nacional do Turismo: uma análise crí- } \\
\text { tica }\end{array}$ & $\begin{array}{l}\text { Davis Gruber Sansolo \& Rita } \\
\text { de Cássia Ariza da Cruz }\end{array}$ & CVT & 2003 & 8 \\
\hline $\begin{array}{l}\text { Revisitando significados em sustentabilidade } \\
\text { no planejamento turístico }\end{array}$ & $\begin{array}{l}\text { Marta de Azevedo Irving; Ivan } \\
\text { Bursztyn; Altair Sancho \& } \\
\text { Gustavo de M. Melo }\end{array}$ & CVT & 2005 & 8 \\
\hline $\begin{array}{l}\text { A rede de negócios do turismo: um estudo so- } \\
\text { bre suas características e implicações estraté- } \\
\text { gicas }\end{array}$ & $\begin{array}{l}\text { Denis Donaire; Marcos Pe- } \\
\text { reira da Silva \& Marcos Anto- } \\
\text { nio Gaspar }\end{array}$ & RTVA & 2009 & 7 \\
\hline $\begin{array}{l}\text { Ensino superior em turismo e hotelaria no } \\
\text { Brasil: um estudo exploratório }\end{array}$ & Rivanda Meira Teixeira & RTA & 2001 & 7 \\
\hline $\begin{array}{l}\text { A aproximação entre o estudo do turismo e a } \\
\text { ciência da administração a luz do modelo Ted- } \\
\text { qual: caso São Luís }\end{array}$ & $\begin{array}{l}\text { Anderson Lourenço Miranda } \\
\text { Lourenço Miranda \& Deborah } \\
\text { Moraes Zouain }\end{array}$ & RTVA & 2008 & 6 \\
\hline $\begin{array}{l}\text { Avaliação da qualidade dos serviços em uma } \\
\text { pousada com a aplicação da escala Servqual }\end{array}$ & $\begin{array}{l}\text { Luciana Santos Veiga \& Josi- } \\
\text { vania Silva Farias }\end{array}$ & RTVA & 2005 & 5 \\
\hline $\begin{array}{l}\text { Globalização do turismo - comunicação e } \\
\text { concorrência no mercado internacional }\end{array}$ & Mario Carlos Beni & RTA & 1996 & 5 \\
\hline $\begin{array}{l}\text { Produção científica em turismo: análise de es- } \\
\text { tudos referenciais no exterior e no Brasil }\end{array}$ & Mirian Rejowski & RTA & 2010 & 5 \\
\hline $\begin{array}{l}\text { Sistema de Turismo - SISTUR: estudo do tu- } \\
\text { rismo face à moderna Teoria de Sistemas }\end{array}$ & Mario Carlos Beni & RTA & 1990 & 5 \\
\hline $\begin{array}{l}\text { Turismo de base comunitária: a participação } \\
\text { como prática no desenvolvimento de proje- } \\
\text { tos turístico no Brasil - Prainha do Canto } \\
\text { Verde, Beberibe (CE) }\end{array}$ & $\begin{array}{l}\text { Marta de Azevedo Irving \& } \\
\text { Teresa Cristina de Miranda } \\
\text { Mendonça }\end{array}$ & CVT & 2004 & 5 \\
\hline $\begin{array}{l}\text { Turismo sustentado para a preservação do } \\
\text { patrimônio ambiental }\end{array}$ & $\begin{array}{l}\text { Doris van de Meene Rusch- } \\
\text { mann }\end{array}$ & RTA & 1992 & 5 \\
\hline
\end{tabular}

Se o foco da análise for reduzido para as referências feitas em artigos publicados nos últimos 5 anos do período de análise (2010-2014), a lista de trabalhos mais refe- renciados muda bastante, revelando novos artigos com maior impacto, conforme apresentado na Tabela 5. 
Tabela 5 - Artigos brasileiros de turismo mais citados em trabalhos publicados a partir de 2010

\begin{tabular}{|c|c|c|c|c|}
\hline Título & Autor(es) & Periódico & Ano & Citações \\
\hline $\begin{array}{l}\text { A rede de negócios do turismo: um } \\
\text { estudo sobre suas características e } \\
\text { implicações estratégicas }\end{array}$ & $\begin{array}{l}\text { Denis Donaire; Marcos Pereira da Silva \& } \\
\text { Marcos Antonio Gaspar }\end{array}$ & RTVA & 2009 & 7 \\
\hline $\begin{array}{l}\text { A aproximação entre o estudo do } \\
\text { turismo e a ciência da administra- } \\
\text { ção a luz do modelo Tedqual: caso } \\
\text { São Luís }\end{array}$ & $\begin{array}{l}\text { Anderson Lourenço Miranda Lourenço } \\
\text { Miranda \& Deborah Moraes Zouain }\end{array}$ & RTVA & 2008 & 6 \\
\hline $\begin{array}{l}\text { Plano Nacional do Turismo: uma } \\
\text { análise crítica }\end{array}$ & $\begin{array}{l}\text { Davis Gruber Sansolo \& Rita de Cássia } \\
\text { Ariza da Cruz }\end{array}$ & CVT & 2008 & 5 \\
\hline $\begin{array}{l}\text { Produção científica em turismo: } \\
\text { análise de estudos referenciais no } \\
\text { exterior e no Brasil }\end{array}$ & Mirian Rejowski & RTA & 2010 & 5 \\
\hline $\begin{array}{l}\text { Revisitando significados em sus- } \\
\text { tentabilidade no planejamento tu- } \\
\text { rístico }\end{array}$ & $\begin{array}{l}\text { Marta de Azevedo Irving; Ivan Bursztyn, } \\
\text { Altair Sancho \& Gustavo de M. Melo }\end{array}$ & CVT & 2005 & 5 \\
\hline $\begin{array}{l}\text { Turismo de base comunitária: a } \\
\text { participação como prática no de- } \\
\text { senvolvimento de projetos turís- } \\
\text { tico no Brasil - Prainha do Canto } \\
\text { Verde, Beberibe (CE) }\end{array}$ & $\begin{array}{l}\text { Marta de Azevedo Irving } \\
\text { Teresa Cristina de Miranda Mendonça }\end{array}$ & CVT & 2004 & 5 \\
\hline
\end{tabular}

Das 3.876 referências a livros brasileiros da área de turismo, $3010(77,7 \%)$ se referem a livros autorais, ao passo que os 866 restantes dizem respeito a livros organizados ou editados. Ao todo, são referenciados 715 livros autorais diferentes. 0 livro autoral mais citado é Análise Estrutural do Turismo de Mario Carlos Beni, obra que recebeu $66 \%$ mais citações do que o segundo colocado no ranking de livros mais citados. Apenas 11 livros receberam ao menos 30 citações. Essa lista é apresentada na Tabela 6.
Se a lista apresentada na Tabela 6 for refeita, considerando-se apenas as referências feitas em trabalhos publicados a partir de 2010, o resultado é essencialmente o mesmo. As primeiras posições entre os livros autorais mais citados não mudam significativamente na comparação entre os trabalhos o total de artigos e os artigos mais recentes. Portanto, nota-se que os mesmos livros seguem apresentando os maiores níveis de impacto na produção científica nacional de turismo. 
Tabela 6 - Livros autorais brasileiros de turismo mais citados

\begin{tabular}{lll}
\hline Título & Autor(es) & Citações \\
\hline $\begin{array}{l}\text { Análise estrutural do turismo } \\
\text { Turismo e planejamento sustentável: a proteção do meio am- }\end{array}$ & Mario Carlos Beni & 169 \\
biente & Doris van de Meene Ruschmann & 102 \\
$\begin{array}{l}\text { Sociologia do Turismo: para uma nova compreensão do lazer e } \\
\text { das viagens }\end{array}$ & Jost Krippendorf & 87 \\
Métodos e técnicas de pesquisa em turismo & Ada de Freitas Maneti Dencker & 67 \\
Turismo: princípios e prática & Chris Cooper; John Fletcher; Ste- & 59 \\
& phen Wanhill; David Gilbert \& Re- & \\
Manual de iniciação ao estudo do turismo & becca Shepherd & 50 \\
Política de turismo e território & Margarita Barretto & 41 \\
$\begin{array}{l}\text { O olhar do turista: lazer e viagens nas sociedades contemporâ- } \\
\text { neas }\end{array}$ & Rita de Cássia Ariza da Cruz Urry & 38 \\
Turismo: fundamentos e dimensões & José Vicente de Andrade & 36 \\
Turismo: princípios, práticas e filosofias & Charles R. Goeldner; J. R. Brent & 34 \\
Planejamento do espaço turístico & Ritchie \& Robert W. Mcintosh & 31
\end{tabular}

As 866 referências a livros nacionais de turismo organizados ou editados dizem respeito a 103 títulos distintos. Apenas 8 livros são citados ao menos 30 vezes. Os dois livros deste conjunto com maior quantidade de citações foram organizados por Adyr Balastreri Rodrigues. Os livros mais citados deste ranking são apresentados na Tabela 7.

Tabela 7 - Livros organizados de turismo mais citados

\begin{tabular}{lll}
\hline Título & Autor(es) & Citações \\
\hline $\begin{array}{l}\text { Turismo e geografia: reflexões teóricas e enfoques regio- } \\
\text { nais }\end{array}$ & Adyr Balastreri Rodrigues & 44 \\
$\begin{array}{l}\text { Turismo e desenvolvimento local } \\
\text { Análises regionais e globais do turismo brasileiro }\end{array}$ & Adyr Balastreri Rodrigues & 43 \\
& $\begin{array}{l}\text { Luiz Gonzaga Godoi Trigo; Alexandre Pa- } \\
\text { nosso Netto; Paulos dos Santos Pires; }\end{array}$ \\
Turismo: teoria e prática - Beatriz Helena Gelas Lage & Mariana Aldrigui Carvalho & Paulo Cesar Milone \\
Turismo global & Willian F. Theobald & 35 \\
Turismo e identidade local: uma visão antropológica & $\begin{array}{l}\text { Álvaro Banducci Júnior \& Margarita Bar- } \\
\text { retto }\end{array}$ & 33 \\
Turismo: espaço, paisagem e cultura & Eduardo Yázigi & 32 \\
Ecoturismo: um guia para planejamento e gestão & Donald E. Hawkins \& Kreg Lindberg & 30 \\
\hline
\end{tabular}

Se forem consideradas apenas as referências feitas por artigos publicados a partir de 2010, a lista de livros organizados mais citados sofre algumas poucas alterações relevantes. Essencialmente, nota-se a perda de destaque dos livros organizados pela pesquisadora Adyr Balastreri Rodrigues. De outro lado, o livro Turismo de base comunitária: diversidade de olhares e experiências brasileiras, de Davis Gruber Sansolo, Roberto Bar- 
tholo e Ivan Bursztyn surge na segunda posição do ranking, colocando-se atrás apenas do livro Análises regionais e globais do turismo brasileiro.

\subsection{Autoria de livros e artigos brasileiros de turismo}

Ao todo, 1.346 autores foram citados no conjunto de artigos e livros nacionais da área de turismo referenciados. $\mathrm{O}$ autor mais citado é o Mario Carlos Beni, com 227 citações. Em seguida neste ranking aparecem Doris van de Meene Ruschmann e
Margarita Barretto. Um total de 33 autores receberam ao menos 30 citações. Dentre estes, $14(42,4 \%)$ são estrangeiros que publicaram no Brasil, com destaque para Jost Krippendorf e John Swarbrooke. Apenas 6,5\% das citações recebidas por estes 33 autores mais referenciados dizem respeito a trabalhos publicados em periódicos, sendo que a grande maioria das citações $(93,5 \%)$ fazem referência a livros autorais. Na contramão dessa tendência, todos os trabalhos citados da pesquisadora Rivanda Meira Teixeira foram publicados em periódicos. A lista de autores mais citados é apresentada na Tabela 8.

Tabela 8 - Autores mais citados (continua)

\begin{tabular}{|c|c|c|c|c|}
\hline \multirow[b]{2}{*}{ Autor } & \multicolumn{4}{|c|}{ Citações } \\
\hline & Livro & Periódico (a) & Total (b) & $(a) /(b)$ \\
\hline Mario Carlos Beni & 210 & 17 & 227 & $7,5 \%$ \\
\hline Doris van de Meene Ruschmann & 148 & 12 & 160 & $7,5 \%$ \\
\hline Margarita Barretto & 133 & 14 & 147 & $9,5 \%$ \\
\hline Jost Krippendorf & 87 & 0 & 87 & $0,0 \%$ \\
\hline John Swarbrooke & 79 & 0 & 79 & $0,0 \%$ \\
\hline Ada de Freitas Maneti Dencker & 78 & 1 & 79 & $1,3 \%$ \\
\hline Reinaldo Dias & 76 & 2 & 78 & $2,6 \%$ \\
\hline Chris Cooper & 72 & 0 & 72 & $0,0 \%$ \\
\hline Luiz Gonzaga Godoi Trigo & 70 & 1 & 71 & $1,4 \%$ \\
\hline Rebecca Shepherd & 69 & 0 & 69 & $0,0 \%$ \\
\hline Rita de Cássia Ariza da Cruz & 55 & 8 & 63 & $12,7 \%$ \\
\hline John Fletcher & 59 & 4 & 63 & $6,3 \%$ \\
\hline Stephen Wanhill & 59 & 0 & 59 & $0,0 \%$ \\
\hline David Gilbert & 59 & 0 & 59 & $0,0 \%$ \\
\hline Geraldo Castelli & 54 & 0 & 54 & $0,0 \%$ \\
\hline Alexandre Panosso Netto & 45 & 4 & 49 & $8,2 \%$ \\
\hline Luzia Neide Menezes Teixeira Coriolano & 45 & 2 & 47 & $4,3 \%$ \\
\hline Mirian Rejowski & 27 & 18 & 45 & $40,0 \%$ \\
\hline Mario Petrocchi & 45 & 0 & 45 & $0,0 \%$ \\
\hline José Vicente de Andrade & 41 & 0 & 41 & $0,0 \%$ \\
\hline John Urry & 38 & 0 & 38 & $0,0 \%$ \\
\hline Joffre Dumazedier & 38 & 0 & 38 & $0,0 \%$ \\
\hline Eduardo Yázigi & 35 & 1 & 36 & $2,8 \%$ \\
\hline
\end{tabular}


Tabela 8 - Autores mais citados

(conclusão)

\begin{tabular}{llllll}
\multicolumn{7}{c}{ Citações } & & \\
Autor & Livro & Periódico (a) & Total (b) & (a)/(b) \\
\hline Rivanda Meira Teixeira & 0 & 35 & 35 & $100,0 \%$ \\
Robert W. Mcintosh & 34 & 0 & 34 & $0,0 \%$ \\
J. R. Brent Ritchie & 34 & 0 & 34 & $0,0 \%$ \\
Charles R. Goeldner & 34 & 0 & 34 & $0,0 \%$ \\
Roberto C. Boullón & 33 & 0 & 33 & $0,0 \%$ \\
Nelson Carvalho Marcellino & 31 & 1 & 32 & $3,1 \%$ \\
Wilson Abrahão Rabahy & 22 & 9 & 31 & $29,0 \%$ \\
Luiz Renato Ignarra & 31 & 0 & 31 & $0,0 \%$ \\
Colin Michael Hall & 31 & 0 & 31 & $0,0 \%$ \\
Beatriz Helena Gelas Lage & 26 & 4 & 30 & $13,3 \%$ \\
\hline
\end{tabular}

Restringindo-se a análise dos autores mais citados para o conjunto de trabalhos publicados a partir de 2010, algumas alterações são notadas nas 7 primeiras posições, reve- lando tendências de mudança no painel de autores com maior nível de impacto, conforme apresentado na Tabela 9.

Tabela 9 - Autores mais citados em trabalhos publicados a partir de 2010

\begin{tabular}{llllll}
\hline \multicolumn{5}{c}{ Citações } & \\
Autor & Livro & Periódico (a) & Total (b) & (a)/(b) \\
\hline Mario Carlos Beni & 95 & 1 & 96 & $1,1 \%$ \\
Doris van de Meene Ruschmann & 62 & 1 & 63 & $1,6 \%$ \\
Margarita Barretto & 56 & 5 & 61 & $8,9 \%$ \\
Reinaldo Dias & 42 & 2 & 44 & $4,8 \%$ \\
Alexandre Panosso Netto & 36 & 4 & 40 & $11,1 \%$ \\
Rita de Cássia Ariza da Cruz & 33 & 5 & 38 & $15,2 \%$ \\
Ada de Freitas Maneti Dencker & 36 & 1 & 37 & $2,8 \%$ \\
\hline
\end{tabular}

Ao todo, 1.431 organizadores e editores de livros são citados. A organizadora mais citada é Adyr Balastreri Rodrigues com 147 citações. Outros organizadores com mais de 40 citações são Luiz Gonzaga Godoi Trigo (60 citações), Alexandre Panosso Netto (57), Heloisa Turini Bruhns (56), Marilia Gomes dos Reis Ansarah (48) e Margarita Barretto (43).

Ainda que a quantidade de citações recebidas seja um indicador relevante da produção acadêmica dos autores, essa medida tem sido criticada por não valorizar a regularidade de publicações. Um autor com uma única publicação muito citada pode até ter oferecido uma grande contribuição para o desenvolvimento do conhecimento, mas em outra perspectiva pode não ser considerado um profissional altamente produtivo por não ter produzido outros trabalhos relevantes. Como solução alternativa para valorizar a regularidade da produção do autor, tem sido cada vez mais adotado o índice h (Hirsch, 
2005), medida que leva em conta conjuntamente a quantidade de citações e a quantidade de trabalhos. $O$ índice é definido como o número de trabalhos com citações maiores ou iguais a esse número.

Dentre os autores citados nos artigos analisados, a pesquisadora Margarita Barretto é quem tem o mais alto índice $h(h=6)$. Em seguida neste ranking aparece o autor britânico John Swarbrooke com 5 trabalhos citados ao menos 5 vezes. Com índice $h=4$ cons- tam os pesquisadores Doris van de Meene Ruschmann, Geraldo Castelli, Luiz Gonzaga Godoi Trigo e Luzia Neide Menezes Teixeira Coriolano. A lista de pesquisadores com índice $\mathrm{h}$ igual ou superior a 3 é apresentada na Figura 2. Deve-se destacar que este índice $h$ aqui calculado restringe-se à análise das citações feitas nos artigos dos periódicos selecionados para o presente trabalho, de forma que em um universo mais amplo de publicações o índice $h$ de cada autor pode ser maior.

Figura 2 - Índice h por autor

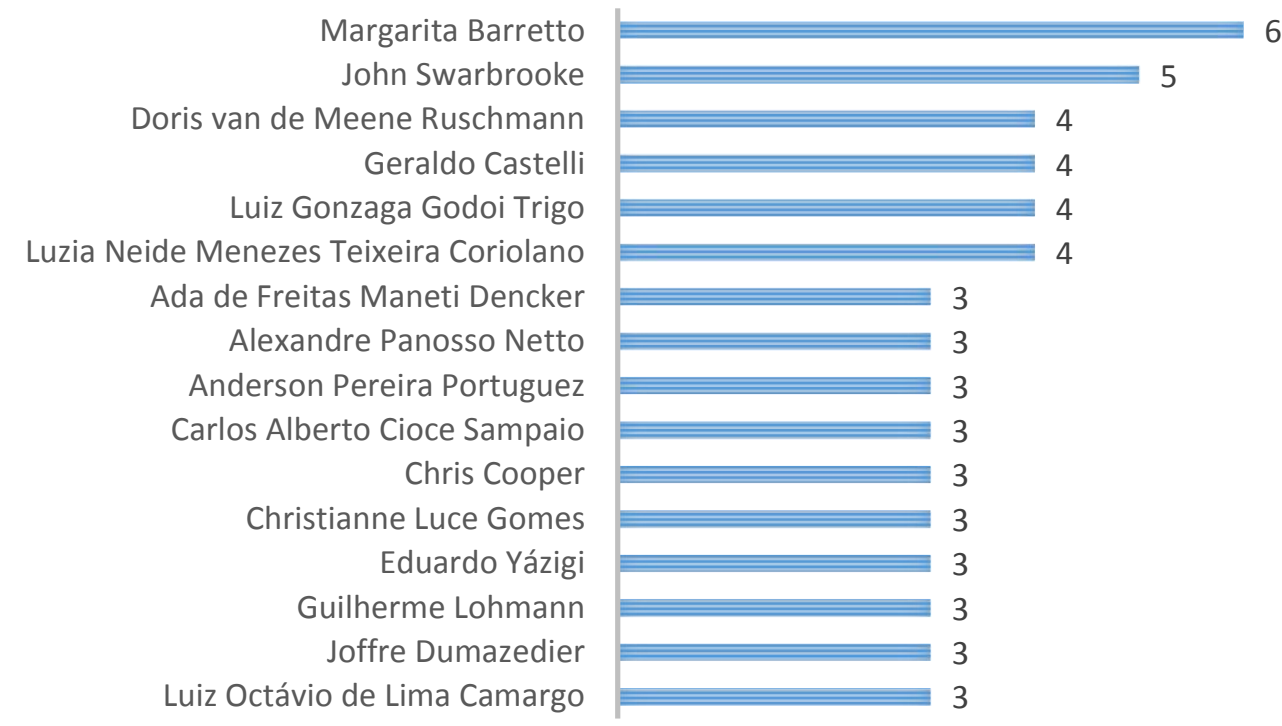

As citações entre autores também foconsideração não apenas o número de citaram estudadas por meio de técnicas de análise de redes sociais, como a elaboração de diagramas de redes e o cálculo de medidas de centralidade (Carrington, Scott, \& Wasserman, 2005; Scott, 2012; Scott \& Carrington, 2011). Duas medidas de centralidade foram calculadas: eigenfactor centrality (EC) e betweeness centrality (BC). $O$ índice EC é uma medida abrangente de centralidade dos autores na rede de citações, levando em ções recebidas, mas também a centralidade dos autores que fizeram estas citações. 0 processo de mensuração é recursivo, de forma que a centralidade de um autor depende da centralidade daqueles que o citam. Desta forma, o EC indica a relevância de um autor de forma muito mais ajustada do que o simples número de citações (Bergstrom, West, \& Wiseman, 2008).

Por sua vez, o BC indica em que me- 
dida os autores conectam outros autores. Um autor com alto BC é aquele que se relaciona com diferentes grupos de autores, muitas vezes tendo o papel de transferir conhecimentos entre diferentes áreas do conhecimento ou grupos sociais. Logo, o BC pode ser utili- zado como indicador de interdisciplinaridade dos autores (Leydesdorff, 2007). Os 20 primeiros colocados nos rankings de autores mais centrais na rede de citações de acordo com os índices EC e BC são apresentados na Tabela 10.

Tabela 10 - Centralidade dos principais autores pelos critérios de eigenfactor e betweeness

\begin{tabular}{|c|c|c|c|}
\hline Autor & $\begin{array}{l}\text { Eigenfactor } \\
\text { centrality (EC) }\end{array}$ & Autor & $\begin{array}{l}\text { Betweeness } \\
\text { centrality } \mathrm{BC} \text { ) }\end{array}$ \\
\hline Mario Carlos Beni & 0,342 & Margarita Barretto & 8,371 \\
\hline Doris van de Meene Ruschmann & 0,309 & Edegar Luis Tomazzoni & 5,634 \\
\hline Margarita Barretto & 0,248 & Rivanda Meira Teixeira & 5,011 \\
\hline José Manoel Gonçalves Gândara & 0,217 & Doris van de Meene Ruschmann & 4,057 \\
\hline Edegar Luis Tomazzoni & 0,184 & John Fletcher & 3,852 \\
\hline Carlos Eduardo Silveira & 0,175 & Adriana Marques Rossetto & 2,988 \\
\hline Juliana Medaglia & 0,171 & Murilo de Alencar Souza Oliveira & 2,988 \\
\hline Mirian Rejowski & 0,154 & Mario Carlos Beni & 2,633 \\
\hline Alexandre Panosso Netto & 0,132 & Mirian Rejowski & 2,421 \\
\hline Ada de Freitas Maneti Dencker & 0,128 & José Manoel Gonçalves Gândara & 1,872 \\
\hline Chris Cooper & 0,122 & Paulo dos Santos Pires & 1,858 \\
\hline Rivanda Meira Teixeira & 0,119 & Glauber Eduardo de Oliveira Santos & 1,695 \\
\hline Rebecca Shepherd & 0,117 & João Carlos Garzel Leodoro da Silva & 1,642 \\
\hline Luiz Gonzaga Godoi Trigo & 0,114 & Carlos Alberto Cioce Sampaio & 1,336 \\
\hline John Fletcher & 0,109 & Luiz Octávio de Lima Camargo & 0,994 \\
\hline Keila Cristina Nicolau Mota & 0,108 & John Westlake & 0,941 \\
\hline Francisco Antonio dos Anjos & 0,107 & Mauri Fortes & 0,831 \\
\hline Valmir Emil Hoffmann & 0,097 & Wanyr Romero Ferreira & 0,831 \\
\hline Jost Krippendorf & 0,096 & Wilson Abrahão Rabahy & 0,817 \\
\hline Heros Augusto Santos Lobo & 0,095 & Ada de Freitas Maneti Dencker & 0,747 \\
\hline
\end{tabular}

O diagrama de todas as citações feitas pelos artigos selecionados a periódicos e livros nacionais de turismo revela uma grande quantidade de ligações entre autores. A profusão de relações torna a rede extremamente complexa e de difícil análise. A rede de citações se torna muito mais simples e fácil de interpretar quando o número de autores incluídos é significativamente reduzido. Neste sentido, a Figura 3 apresenta a rede social formada pelas referências feitas aos 46 pes- quisadores cujos trabalhos receberam ao menos 20 citações no conjunto total de artigos analisados. Esta figura, apesar de omitir um grande número de autores, mostra mais claramente o posicionamento e as relações entre os principais autores. Os autores presentes no canto superior esquerdo do diagrama são aqueles que não se conectam a esta rede reduzida, não citando e não sendo citados por nenhum dos mais autores selecionados. 
Figura 3- Diagrama da rede reduzida de autores e citações

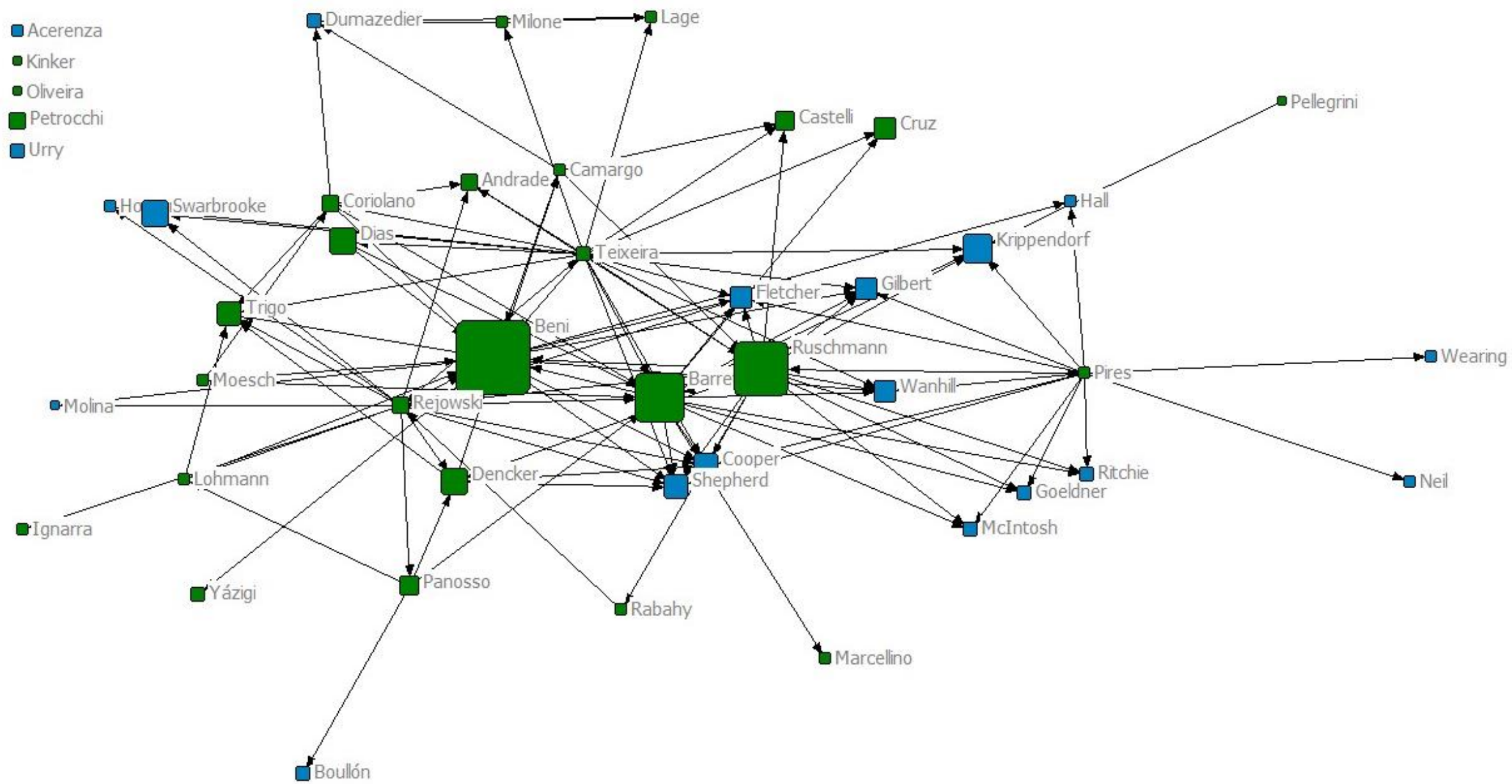

Legenda: Acerenza: Miguel Ángel Acerenza; Andrade: José Vicente de Andrade; Barretto: Margarita Barretto; Beni: Mario Carlos Beni; Boullón: Roberto C. Boullón; Camargo: Luiz Octávio de Lima Camargo; Castelli: Geraldo

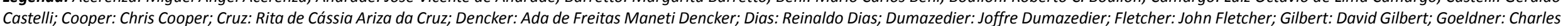
R. Goeldner; Hall: Colin Michael Hall; Horner: Susan Horner; Ignarra: Luiz Renato Ignarra; Kinker: Sônia Kinker; Krippendorf: Jost Krippendorf; Lage: Beatriz Helena Gelas Lage; Lohmann: Guilherme Lohmann; Marcellino: Nelson Carvalho Marcellino; Mcintosh: Robert W. Mcintosh; Milone: Paulo Cesar Milone; Moesch: Marutschka Martini Moesch; Molina: Sergio Molina; Neil: John Neil; Oliveira: Antônio Pereira Oliveira; Panosso: Alexandre Panosso Netto; Pellegrini: Américo Pellegrini Filho; Petrocchi: Mario Petrocchi; Pires: Paulo dos Santos Pires; Rabahy: Wilson Abrahão Rabahy; Rejowski: Mirian Rejowski; Ritchie: J. R. Brent Ritchie; Ruschmann: Doris van de Meene Ruschmann; Shepherd: Rebecca Shepherd; Swarbrooke: John Swarbrooke; Teixeira: Luzia Neide Menezes Teixeira Coriolano; Teixeira: Rivanda Meira Teixeira; Trigo: Luiz Gonzaga Godoi Trigo; Urry: John Urry; Wanhill: Stephen Wanhill; Wearing: Stephen Wearing; Yázigi: Eduardo Yázigi. 
O estudo das relações entre autores incluindo citações a livros e a periódicos não selecionados para análise neste trabalho oferece uma visão interessante das relações entre os trabalhos de diferentes pesquisadores. Contudo, essa perspectiva é acompanhada de certo viés na medida em que mistura possibilidades de relações unidirecionais e bidirecionais. Citações de livros feitas por artigos foram registradas na presente pesquisa, mas citações de artigos feitas em livros não. Com efeito, apenas citações feitas pelos artigos publicados nos quatro periódicos principais foram registradas e analisadas. O mesmo ocorre com artigos publicados em periódicos não selecionados para análise nesta pesquisa. Por isso, uma segunda análise de rede foi elaborada incluindo apenas as referências feitas a artigos publicados nos periódicos analisados. Nesta segunda análise de rede todos os pares de autores permitem relações bidirecionais, ou seja, todos os trabalhos que fazem citações foram ou poderiam ter sido citados também. Este diagrama é apresentado na Figura 4.

A análise da Figura 4 mostra que a rede social formada exclusivamente por artigos publicados nos principais periódicos nacionais de turismo é consideravelmente diferente da rede que inclui livros e outros periódicos. A explicação para tal diferença é o fato já apresentado anteriormente de que as citações a periódicos representam a minoria das citações totais. Isto leva a um menor destaque para alguns pesquisadores mais antigos e cujos nomes se tornaram reconhecidos sobretudo por seus livros. De outrolado, ganham evidência alguns autores com publicações mais recentes e sem grande produção de livros.

\subsection{Periódicos}

Os quatro periódicos selecionados para análise são também os mais citados pelos artigos analisados. A RTA lidera o ranking de periódicos mais citados com 285 menções. Em segundo lugar aparece a RTVA com 228 citações. O CVT recebeu 110 citações e a RBTur 50. A proporção de citações entre as revistas muda consideravelmente se forem considerados apenas as referências feitas em trabalhos publicados a partir de 2010. Com este recorte, a RTVA passa a ocupar a primeira posição do ranking com 178 menções, contra 129 menções da RTA.

O mais citado dentre os periódicos não selecionados para análise é a Revista Acadêmica Observatório de Inovação do Turismo. $\mathrm{Na}$ sequência aparecem a Revista Hospitalidade, a Revista Rosa dos Ventos e o periódico Licere. A relativa pequena citação da Revista Brasileira de Ecoturismo (RBE), apesar de sua classificação no estrato B2 do sistema Qualis em 2014, sustenta a ideia de que se trata de uma publicação voltada para um segmento específico de pesquisadores e relativamente afastada do centro de atenções da área de turismo como um todo. Portanto, essa pequena taxa de citações da RBE contribui para justificar sua não inclusão no conjunto de periódicos analisados neste trabalho. A lista de periódicos mais citados é apresentada na Figura 5. 
Figura 4 - Diagrama da rede reduzida de autores e citações exclusivas dos periódicos selecionados para análise

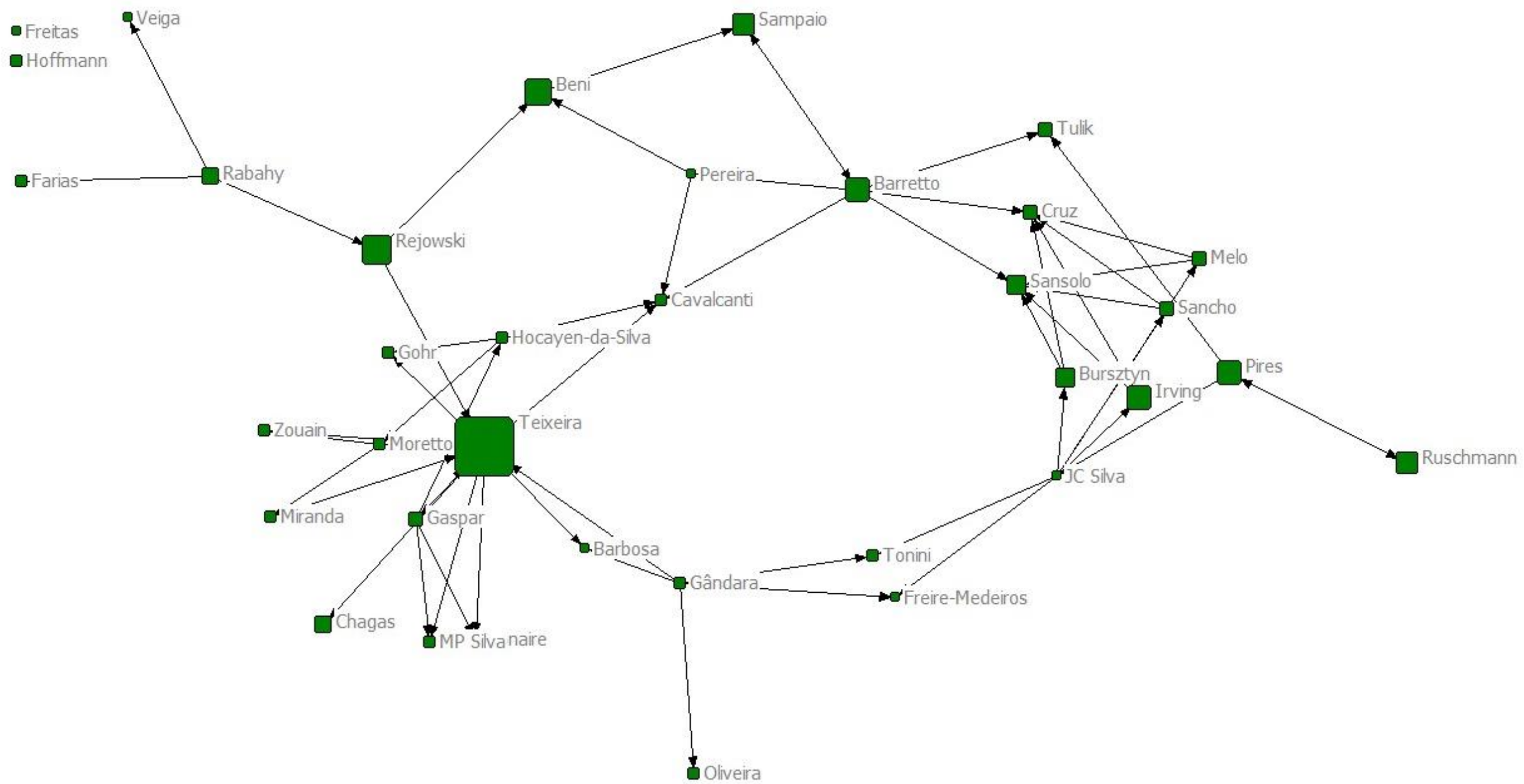

Legenda: Barbosa: Maria de Lourdes de Azevedo Barbosa; Barretto: Margarita Barretto; Beni: Mario Carlos Beni; Bursztyn: Ivan Bursztyn; Cavalcanti: Keila Brandão Cavalcanti; Chagas: Márcio Marreiro das Chagas; Cruz: Rita de Cássia Ariza da Cruz; Donaire: Denis Donaire; Farias: Josivania Silva Farias; Freire-Medeiros: Bianca Freire-Medeiros; Freitas: Rodrigo Randow de Freitas; Gândara: José Manoel Gonçalves Gândara; Gaspar: Marcos Antonio Gaspar: Gohr: Cláudia Fabiana Gohr; Hocayen-da-Silva: Antônio João Hocayen-da-Silva; Hoffmann: Valmir Emil Hoffmann; Irving: Marta de Azevedo Irving: IC Silva: João Carlos Garzel Leodoro da Silva; Melo: Gustavo de M. Melo; Miranda: Anderson Lourenço Miranda Lourenço Miranda; Moretto: Luís Moretto Neto; MP Silva: Marcos Pereira da Silva: Oliveira: Josildete Pereira de Oliveira; Pereira: Cássio Avelino S. Pereira; Pires: Paulo dos Santos Pires; Rabahy: Wilson Abrahão Rabahy; Rejowski: Mirian Rejowski; Ruschmann: Doris van de Meene Ruschmann; Sampaio: Carlos Alberto Cioce Sampaio; Sancho: Altair Sancho; Sansolo: Davis Gruber Sansolo; Teixeira: Rivanda Meira Teixeira; Tonini: Hernanda Tonini; Tulik: Olga Tulik; Veiga: Luciana Santos Veiga; Zouain: Deborah Moraes Zouain; 
Figura 5 - Citações por periódico

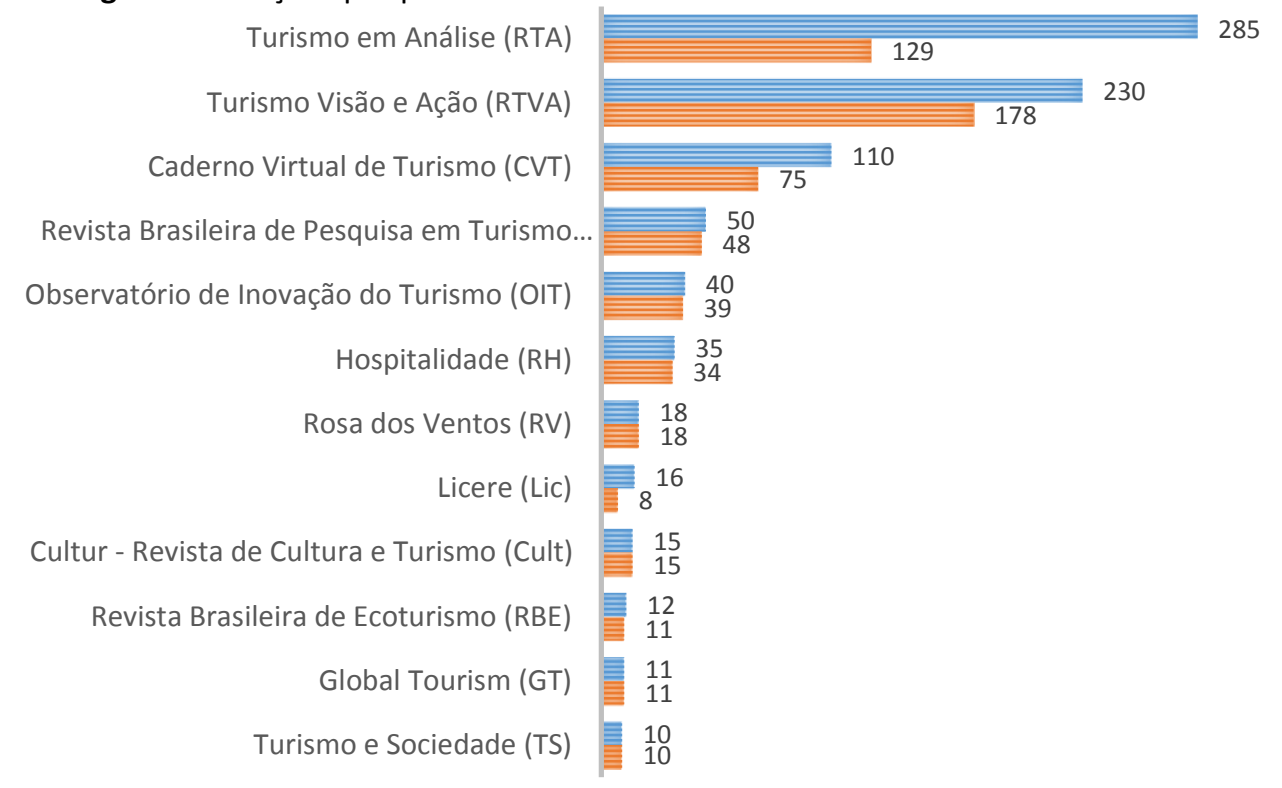

트 Total

를 2010-2014
Uma análise mais cuidadosa da relevância dos trabalhos publicados em periódicos deve levar em consideração não apenas o número de citações, mas também o número total de artigos. Se o número de artigos é desconsiderado, o julgamento da relevância dos artigos de um periódico tende a ficar enviesado em favor dos periódicos com maior quantidade de artigos publicados. Uma forma de contornar esse problema é a análise do fator de impacto, ou seja, a razão entre o número total de citações recebidas e o número total de trabalhos publicados pelo periódico (Garfield, 1999, 2006). Os fatores de impacto calculados para os quatro periódicos selecionados são apresentados na Tabela 12.

No entanto, deve-se ressaltar que o fator de impacto de uma publicação qualquer tende a aumentar à medida em que cresce o número de publicações na mesma área. Assim, os periódicos mais antigos podem ter sua relevância subestimada se comparados aos periódicos mais recentes por meio do fator de impacto calculado sobre o conjunto completo de artigos. A fim de evitar esse tipo de distorção foi calculado também o fator de impacto dos periódicos considerando apenas as publicações ocorridas nos últimos 5 anos. Esses resultados também são apresentados na Tabela 12. Por fim, o índice $h$ foi calculado como uma terceira medida de relevância dos periódicos selecionados. Conforme discutido anteriormente, este índice valoriza não apenas o número total de citações recebidas, mas também o número de artigos que receberam tais citações, desfavorecendo periódicos inconstantes em termos de citações recebidas. $O$ índice $h$ calculado para cada periódico também é apresentado na Tabela 11. 
Tabela 11 - Fator de impacto dos periódicos

\begin{tabular}{llll} 
& \multicolumn{3}{l}{ Fator de Impacto } \\
Periódico & Total & $\mathbf{5}$ anos & Índice $\mathbf{h}$ \\
\hline Turismo em Análise (RTA) & 0,60 & 0,40 & 4 \\
Turismo Visão e Ação (RTVA) & 0,73 & 0,40 & 3 \\
Caderno Virtual de Turismo (CVT) & 0,36 & 0,06 & 5 \\
Revista Brasileira de Pesquisa em Turismo (RBTur) & 0,32 & 0,22 & 4 \\
\hline
\end{tabular}

A análise das citações entre periódicos revela uma rede de relações entre publicações. Essa estrutura é fruto de proximidades temáticas, geográficas, históricas e pessoais, dentre outras. Assim como feito para os autores, essa rede de relações foi estudada por meio da metodologia de análise de redes sociais. O diagrama da rede de citações entre periódicos é apresentado na Figura 6.

No diagrama, os periódicos são representados por quadrados e as citações por linhas que conectam os quadrados. Os tamanhos dos quadrados indicam as quantidades de citações recebidas pelos periódicos, enquanto as cores diferenciam os periódicos selecionados para análise dos demais. Em vermelho são destacados os periódicos selecionados. É importante ressaltar que as citações partem somente dos periódicos analisados, mas se direcionam a qualquer um dos periódicos apresentados. As espessuras das linhas representam o número de citações entre os dois periódicos interconectados.

Nota-se pela que os periódicos RTA e RTVA ocupam posições mais centrais que os demais. A RBTur ocupa uma posição mais central que o CVT, ainda que tenha recebido menos da metade das citações recebidas por este último. A revista Hospitalidade se apresenta mais ao centro da rede do que a Observatório de Inovação do Turismo, mesmo tendo esta última sido citada mais vezes que a primeira. $\mathrm{Na}$ periferia da rede aparecem sobretudo periódicos voltados para temas específicos (como a Tourism and Karst Areas), periódicos recentemente lançados (como a Revista Iberoamericana de Turismo) e periódicos extintos (como a Turismo: Tendências \& Debates).

O diagrama de rede apresentado não traz informações sobre as citações feitas pelos artigos de um periódico a outros artigos do mesmo periódico. Esse tipo de citação pode ser considerado como um indicador de endogenia dos periódicos. O percentual de citações deste tipo sobre o total de citações feitas na RTA é de 50,6\%. Essa 'taxa de endogenia' é de $46,6 \%$ na RTVA, $36,7 \%$ no CVT e $15,2 \%$ RBTur. Contudo, a análise comparativa dessas taxas deve ser cautelosa, já que as 'taxas de endogenia' relativamente altas da RTA e da RTVA têm relação com a própria idade desses periódicos, uma vez que durante anos não haviam outros periódicos brasileiros para serem citados.

A análise das categorias de trabalhos referenciados feita anteriormente pode ser detalhada por periódico. Com respeito ao tipo dos trabalhos referenciados, a RBTur se destaca por ter a taxa mais alta de referenciação de trabalhos publicados em periódicos $(44,5 \%$ das referências totais de periódicos e livros). 
No outro extremo está o CVT, cuja taxa de re- trangeiros (27,3\%). Por fim, com respeito à ferenciação de periódicos é de apenas $23,1 \%$. área de conhecimento, os quatro periódicos O CVT também se apresenta como o menos in- apresentam taxas similares de utilização de reternacionalizado dos periódicos analisados, ferências específicas da área de turismo. A sendo que $72,7 \%$ dos trabalhos citados por taxa de citação de cada categoria de material seus artigos são nacionais. A RBTur se des- para os periódicos selecionados é apresentada taca positivamente também neste quesito na Tabela 12.

como o periódico que mais cita trabalhos es-

Tabela 12 - Taxa de citação de materiais por categoria e periódico

\begin{tabular}{l|lll|llll|lll}
\hline & Tipo & & & \multicolumn{2}{|c|}{ Nacionalidade } & & \multicolumn{3}{|c}{ Área do conhecimento } \\
Periódico & Periódico & Livro & Total & Sim & Não & Total & Turismo & Outra & Total \\
\hline CVT & $23,1 \%$ & $76,9 \%$ & $100,0 \%$ & $72,7 \%$ & $27,3 \%$ & $100,0 \%$ & $42,8 \%$ & $57,2 \%$ & $100,0 \%$ \\
RBTur & $44,5 \%$ & $55,5 \%$ & $100,0 \%$ & $44,8 \%$ & $55,2 \%$ & $100,0 \%$ & $42,8 \%$ & $57,2 \%$ & $100,0 \%$ \\
RTA & $34,1 \%$ & $65,9 \%$ & $100,0 \%$ & $53,8 \%$ & $46,2 \%$ & $100,0 \%$ & $41,0 \%$ & $59,0 \%$ & $100,0 \%$ \\
RTVA & $38,2 \%$ & $61,8 \%$ & $100,0 \%$ & $59,4 \%$ & $40,6 \%$ & $100,0 \%$ & $35,5 \%$ & $64,5 \%$ & $100,0 \%$ \\
\hline
\end{tabular}


Figura 6 - Rede de relações entre periódicos brasileiros de turismo

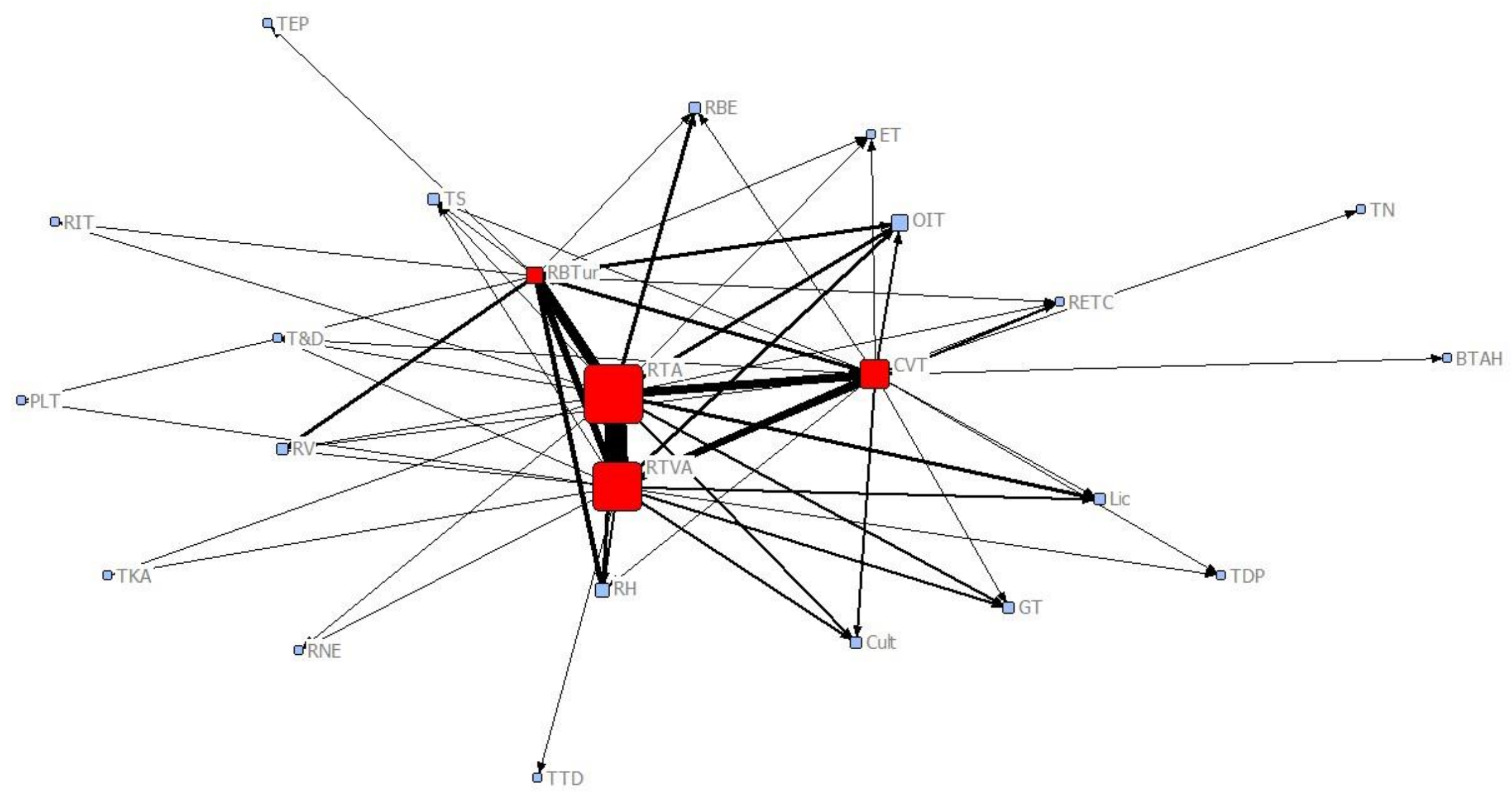

Legenda: BTAH: Boletim de Turismo e Administração Hoteleira; CVT: Caderno Virtual de Turismo; Cult: Cultur: Revista de Cultura e Turismo; ET: Estudos Turisticos; GT: Global Tourism; RH: Hospitalidade; Lic: Licere; OIT: Observatório de Inovação do Turismo; PLT: Patrimônio: Lazer e Turismo; RBE: Revista Brasileira de Ecoturismo; RBTur: Revista Brasileira de Pesquisa em Turismo; RETC: Revista Eletrônica de Turismo Cultural; RIT: Revista Iberoamericana de Turismo; RNE: Revista Nordestina de Ecoturismo; RV: Rosa dos Ventos; TKA: Tourism and Karst Areas; TN: Turis Nostrum; T\&D: Turismo \& Desenvolvimento; TS: Turismo e Sociedade; RTA: Turismo em Análise; RTVA: Turismo Visão e Ação; TDP: Turismo: Dimensões e Perspectivas; TEP: Turismo: Estudos e Práticas; TTD: Turismo: Tendências \& Debates 


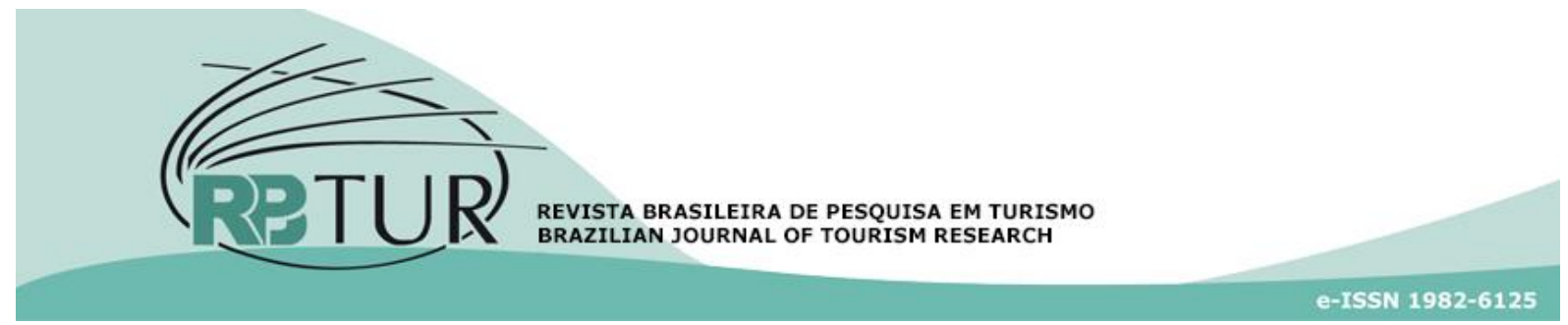

\subsection{Temas}

Uma breve análise das palavras-chave dos artigos citados em comparação com as mesmas informações dos artigos publicados nos quatro periódicos selecionados revela um pouco sobre o diferente nível de impacto dos diversos temas. $O$ fator de impacto calculado para os artigos indexados por cada uma das 20 palavras-chave mais utilizadas, conforme apresentado na Figura 7, mostra que hospitalidade é o tema com maior impacto, sendo este seguido por planejamento turístico, hotelaria e cultura. Nota-se também que, mesmo para estes termos mais bem-sucedidos, os fatores de impacto são relativamente baixos, não chegando a 0,07.

Figura 7 - Fator de impacto por palavras-chave mais utilizadas 0,067

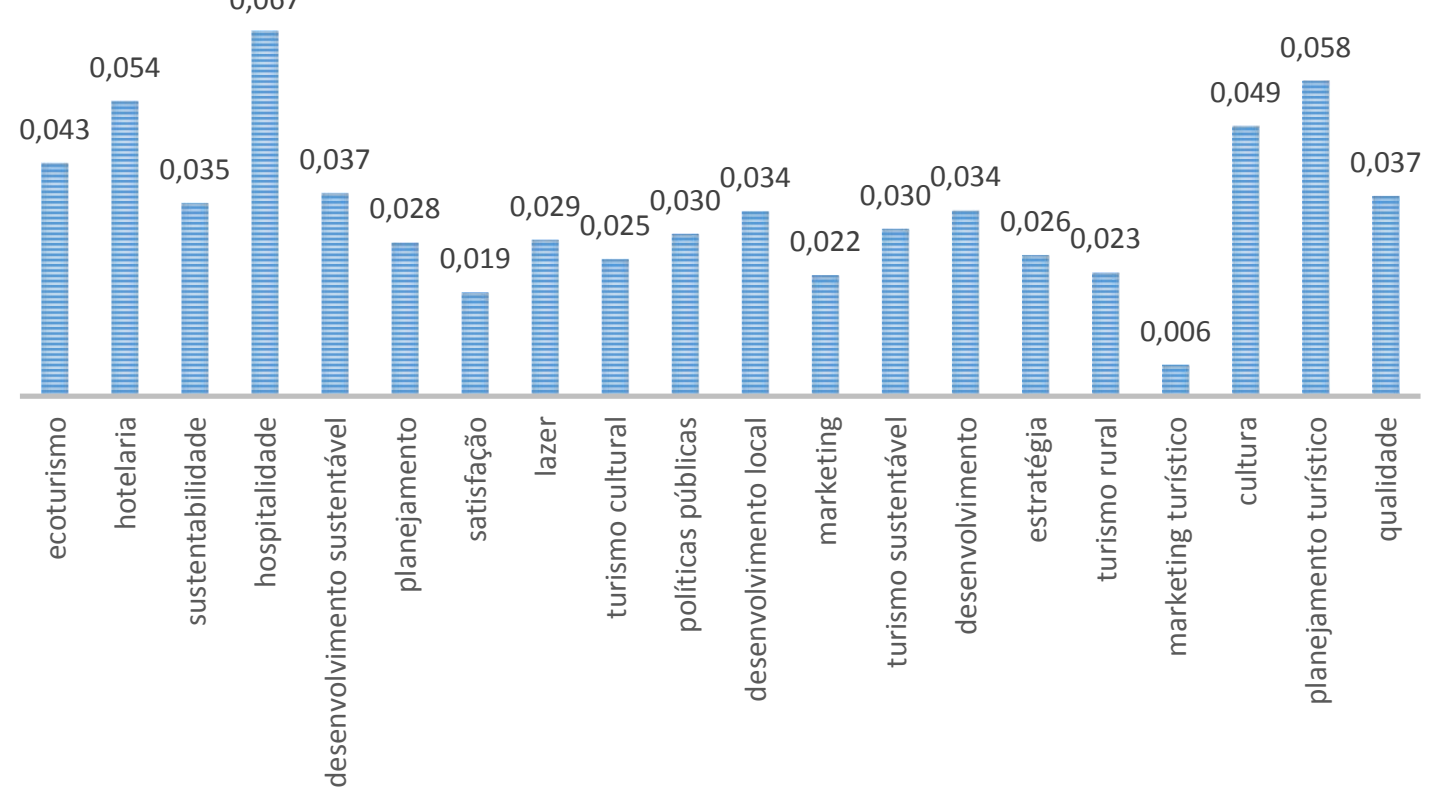

\section{CONSIDERAÇÕES FINAIS}

O presente estudo analisou todas as referências feitas pelos artigos publicados nas quatro principais revistas de turismo do Brasil. Este foi um trabalho pioneiro no contexto abordado, oferecendo informações bibliométricas inéditas sobre a produção científica brasileira de turismo. Diversas listas, medidas, índices e diagramas foram apresentados, disponibilizando uma série de elemen- tos úteis para orientar pesquisadores, editores e gestores de pesquisa em suas atividades. Em particular, este trabalho contribui para o desenvolvimento de indicadores de impacto de autores e periódicos, métrica amplamente utilizada atualmente para a avaliação de docentes e programas de pós-graduação no Brasil.

Os resultados obtidos mostram que a pesquisa científica brasileira em turismo ainda apresenta algumas características de 
áreas incipientes. Alguns dos elementos que apontam essa direção é a relativa pequena citação de artigos publicados em periódicos científicos, a preferência por referências estrangeiras e por trabalhos publicados em outras áreas do conhecimento. Outra evidência dessa condição é o pequeno número de referências recebidas pelos artigos mais citados, indicando que a área ainda está longe de estabelecer o que poderia ser conhecido como artigos clássicos. Além disso, ainda que a amplitude da análise seja limitada, excluindo as referências feitas por livros e outros tipos de materiais, nota-se que o número de citações recebidas e o índice $\mathrm{h}$ dos principais autores são relativamente reduzidos. $O$ pesquisador Mario Carlos Beni, autor mais citado nos artigos analisados, recebeu 227 menções. A pesquisadora Margarita Barretto, que ocupa a liderança no ranking do índice $h$ ora calculado, tem um índice de apenas 6. Para fins de comparação, de acordo com dados do Google Scholar, o pesquisador da universidade neozelandesa de Canterbury, Colin Michael Hall, recebeu mais de 30 mil citações e tem um índice $\mathrm{h}$ de 90 . O pesquisador Dimitrios Buhalis, da Bournemouth University, recebeu perto de 15 mil citações e seu índice $h$ é 53. No Brasil, o Google Scholar apresenta Luiz Gonzaga Godoi Trigo com o índice h 21, o mais alto entre os pesquisadores de turismo, e cerca de 1700 citações. Mario Carlos Beni, por sua vez, recebeu por volta de $3 \mathrm{mil}$ citações, mas seu índice h é 11 . Ainda a título de comparação, o pesquisador brasileiro com atuação há vários anos no exterior, GuiIherme Lohmann, tem por volta de 660 citações e índice h 11 no Google Scholar. A pesquisadora Margarita Barretto não tem perfil no Google Scholar ou seu perfil é tem acesso restrito, portanto não foi possível identificar seu índice nesta base. Por fim, deve-se ressaltar que o fator de impacto das revistas científicas brasileiras de turismo também é relativamente baixo. No conjunto analisado, é a Revista Turismo Visão e Ação quem apresenta o fator de impacto mais alto: 0,73. Apesar do destaque nacional, esse valor pode ser considerado baixo se comparado ao fator de impacto mais alto de uma revista de turismo internacional: 2,68, do periódico Annals of Tourism Research.

Apesar dos resultados apontarem certo grau de fragilidade da produção científica brasileira de turismo, essas informações devem ser consideradas dentro de seu contexto. Os artigos analisados versavam, em sua maioria, sob aspectos da realidade brasileira do turismo e, como era de se esperar, despertaram maior interesse pelos acadêmicos brasileiros. Além disso, a área acadêmica de turismo no Brasil é reduzida e possuía no início de 2016 somente 11 programas de pósgraduação stricto sensu, desses 4 são de doutorado e mestrado (UNIVALI, UFRN, UCS e UAM). Na grande área CAPES de Administração, Ciências Contábeis e Turismo existiam 182 programas cadastrados em agosto de 2015 (CAPES, 2016). Ou seja, a área de turismo representa apenas $6,7 \%$ do total de programas desta área CAPES. Assim, é de se imaginar que o corpo docente e discente que produz conhecimentos na área não é tão grande, fato que leva aos incipientes números de artigos, citações e índices que foram demonstrados. Importa também observar que não foi analisada a qualidade dos estudos publicados nem seu impacto positivo na 
sociedade, tais como geração de produtos ou patentes, melhoria de vida da sociedade e inovação. A geração de tais impactos positivos deveria ser um dos principais motivos pelos quais se faz pesquisa em turismo no Brasil.

De fato, deve-se reconhecer as dificuldades enfrentadas pela pesquisa no Brasil em comparação com a realidade de alguns outros países, além das dificuldades da área de turismo perante áreas mais antigas e consolidadas do conhecimento. Além disso, algumas comparações entre as referências feitas pelo conjunto completo de artigos analisados e aquelas feitas somente pelos artigos publicados a partir de 2010 revelam que a área de turismo no Brasil é dinâmica. Novos pesquisadores e periódicos tem ganhado importância como referências. Desta forma, uma rota possível para a pesquisa em turismo no Brasil é a do aprimoramento e consolidação.

\section{REFERÊNCIAS}

Barretto, M. (1996). Produção Bibliográfica em Turismo no Brasil. Turismo em Análise, $7(2)$.

Bergstrom, C. T., West, J. D., \& Wiseman, M. A. (2008). The Eigenfactor ${ }^{\mathrm{TM}}$ metrics. The Journal of Neuroscience, 28(45), 1143311434.

Bertero, C. O., Caldas, M. P., \& Wood Jr., T. (1999). Produção científica em administração de empresas: provocações, insinuações e contribuições para um debate local. Revista de Administração Contemporânea, 3(1), 147178.

CAPES. (2016). Plataforma Sucupira. Recuperado em 12 fev. 2016 de

\section{http://sucupira.capes.gov.br/}

Carrington, P. J., Scott, J., \& Wasserman, S. (2005). Models and Methods in Social Network Analysis: Cambridge University Press.

Cheng, C. K., Li, X. R., Petrick, J. F., \& O'Leary, J. T. (2011). An examination of tourism journal development. Tourism Management, 32(1), 53-61.

CNPq. (2016). Estatísticas e indicadores. Recuperado em 11 fev., 2016, de http://www.cnpq.br/apresentacao3.

FAPESP. (2005). Indicadores de ciência, tecnologia e inovação em São Paulo 2004. São Paulo: FAPESP.

Garfield, E. (1999). Journal impact factor: a brief review. Canadian Medical Association Journal, 161(8), 979-980.

Garfield, E. (2006). The history and meaning of the journal impact factor. JAMA, 295(1), 90-93.

Hall, C. M. (2011). Publish and perish? Bibliometric analysis, journal ranking and the assessment of research quality in tourism. Tourism Management, 32(1), 16-27.

Hirsch, J. E. (2005). An index to quantify an individual's scientific research output. Proceedings of the National Academy of Sciences of the United States of America, 102(46), 16569-16572.

Jamal, T., Smith, B., \& Watson, E. (2008). Ranking, rating and scoring of tourism journals: Interdisciplinary challenges and innovations. Tourism Management, 29(1), 66-78. 
Leydesdorff, L. (2007). Betweenness centrality as an indicator of the interdisciplinarity of scientific journals. Journal of the American Society for Information Science and Technology, 58(9), 1303-1319.

McKercher, B., Law, R., \& Lam, T. (2006). Rating tourism and hospitality journals. Tourism Management, 27(6), 1235-1252.

Meis, L., Arruda, A. P., \& Guimarães, J. (2007). The Impact of Science in Brazil. IUBMB Life, 59(4-5), 227-234.

Mendes, P. H. C., Martelli, D. R. B., Souza, W. P. d., Quirino Filho, S., \& Martelli Júnior, H. (2010). Perfil dos pesquisadores bolsistas de produtividade científica em medicina no CNPq, Brasil. Revista Brasileira de Educação Médica, 34, 535-541.

Miranda, E. C. d. (2012). Periódicos científicos de Turismo e Hospitalidade no Brasil. (Mestrado em Hospitalidade Dissertação), Universidade Anhembi-Morumbi, São Paulo.

Moreno-Gil, S., \& Picazo-Peral, P. (2012). Difusión de la investigación científica en revistas de turismo realizada por instituiciones españolas. Revista de Análisis Turístico, 14, 33-52.

Mugnaini, R., Jannuzzi, P. d. M., \& Quoniam, L. (2004). Indicadores bibliométricos da produção científica brasileira: uma análise a partir da base Pascal. Ciência da Informação, 33(2), 123-131.

Panosso Netto, A. (2005). Publicações em turismo no Brasil. In L. G. G. Trigo, A. Panosso Netto, M. A. Carvalho \& P. d. S. Pires (Eds.), Análises regionais e globais do turismo brasileiro (pp. 257-273). São Paulo: Roca.
Panosso Netto, A., \& Calciolari, G. F. d. M. (2010). Quantos são os livros teóricos de turismo publicados no brasil? uma análise da produção bibliográfica nacional (1990-2010). Turismo em

Análise, 21(3), 668-686.

Panosso Netto, A., \& Jäger, M. (2015). Robert Glücksmann (1877-1942): founder of Berlin School of Tourism Research. Anatolia, 1-10.

Park, K., Phillips, W. J., Canter, D. D., \& Abbott, J. (2011). Hospitality and tourism research rankings by author, university, and country using six major journals: the first decade of the new millenium. Journal of Hospitality \& Tourism Research, 35(3), 381416.

Pechlaner, H., Zehrer, A., Matzler, K., \& Abfalter, D. (2004). A ranking of international tourism and hospitality journals. Journal of Travel Research,

42(4), 328-332.

Picazo-Peral, P., Moreno-Gil, S., \& LeónGonzález, C. J. (2012). Difusión de la investigación científica de turismo en Brasil. Cultur: Revista de Cultura e Turismo, 6(4), 436.

Rejowski, M., \& Aldrigui, M. (2007). Periódicos Científicos em Turismo no Brasil: dos boletins técnico-informativos ás revistas cientificas eletrônicas. Turismo em Análise, 18(2), 245-268.

Romano-Silva, M. A., Correa, H., Oliveira, M. C. L., Quirino, I. G., Colosimo, E. A., Martelli, D. R., ... Oliveira, E. A. (2013). Perfil e análise da produção científica dos pesquisadores brasileiros em Neurociência Clínica. Revista de Psiquiatria Clínica, 40(2), 53-58. 
Ryan, C. (2005). The ranking and rating of academics and journals in tourism research. Tourism Management, 26(5), 657-662.

Sacardo, M. S., \& Hayashi, M. C. P. I. (2011). Balanço bibliométrico da produção científica em Educação Física e Educação Especial oriunda de teses e dissertações. Revista Brasileira de Pós-Graduação, 8(15), 111-135.

Santos, G. E. d. O. (2016). Publicações de Turismo. Recuperado em 11 de fev., 2016, de

\section{http://www.publicacoesdeturismo.com.br/.}

Santos, G. E. d. O., \& Rejowski, M. (2013). Comunicação científica em turismo no Brasil: análises descritivas de periódicos nacionais entre 1990 e 2012. Revista Brasileira de Pesquisa em Turismo, 7(1), 149-167.

Scott, J. (2012). Social Network Analysis: SAGE Publications.

Scott, J., \& Carrington, P. J. (2011). The SAGE Handbook of Social Network Analysis: SAGE Publications.

Severt, D. E., Tesone, D. V., Bottorff, T. J., \& Carpenter, M. L. (2009). A world ranking of the top 100 hospitality and tourism programs. Journal of Hospitality \& Tourism Research, 33(4), 451-470.

Solha, K. T., \& Jacon, M. d. C. M. (2010). Evaluación de revistas científicas eletrónicas brasileñas de turismo: desafios en la búsqueda de calidad. Estudios y Perspectivas en Turismo, 19(2), 182-200.

Viotti, E. B., \& Macedo, M. M. (Eds.). (2003). Indicadores de ciência, tecnologia e inovação no Brasil. Campinas: Ed. Unicamp.

Vitor-Costa, M., Silva, P. M. d., \& Soriano, J. B. (2012). A avaliação da produtividade em pesquisa na Educação Física: reflexões sobre algumas limitações dos indicadores bibliométricos. Revista Brasileira de Educação Física e Esporte, 26(4), 581-597.

Wood Jr, T., \& Chueke, G. V. (2008). Ranking de produção científica em administração de empresas no Brasil. Revista de Administração Mackenzie, 9(4), 13-31.

\section{Dados dos Autores}

\section{Glauber Eduardo de Oliveira Santos}

Escola de Artes, Ciências e Humanidades da Universidade de São Paulo (EACH-USP) - Bacharel em Turismo pela Escola de Comunicações e Artes (ECA) da Universidade de São Paulo (USP), mestre em Ciências da Comunicação na linha de pesquisa de Turismo e Lazer pela ECA-USP, mestre e doutor em Economia do Turismo e do Meio Ambiente na Universidade das Ilhas Baleares (Espanha) e doutor em Administração de Organizações na Faculdade de Economia, Administração e Contabilidade de Ribeirão Preto da USP. É professor do curso de Bacharelado em Lazer e Turismo e do Programa de Pós-Graduação em Turismo da Escola de Artes, Ciências e Humanidades da USP.E-mail: glauber.santos@usp.br

\section{Alexandre Panosso Netto}

Escola de Artes, Ciências e Humanidades da Universidade de São Paulo (EACH-USP) - Formado em Filosofia e em Turismo pela Universidade Católica Dom Bosco (UCDB), doutor em Ciências da Comunicação pela Escola de Comunicações e Artes da Universidade de São Paulo (ECA-USP), Pós-doutor em Turismo pela Universidad Europea Miguel de Cervantes (UEMC-Espanha). Livre-docente pela Escola de Artes, Ciências e Humanidades da Universidade de São Paulo (EACH-USP). É professor do curso de Bacharelado em Lazer e Turismo e coordenador do Mestrado em 
Turismo da EACH-USP. E-mail: pa- (EACH-USP) - Estudante do curso de Bacharenosso@usp.br lado em Lazer e Turismo da Escola de Artes, Ciências e Humanidades da Universidade de

Xuanyi Wang - Escola de Artes, Ciências e Hu- São Paulo (EACH-USP). Foi bolsista PIBIC na manidades da Universidade de São Paulo EACH-USP. Email: xuanyi.wang@usp.br 